\title{
A RATIONALIZED SEISMIC DESIGN METHOD FOR BUILDINGS IN EARTHQUAKE-PRONE DEVELOPING COUNTRIES
}

\author{
Tint Lwin', Takeshi Koike², and Ji Dang ${ }^{3}$ \\ ${ }^{1}$ Equilibrium Structural Design Group, Mandalay, Myanmar, Tel: +95-9-402-592-293, \\ e-mail: mdytintlwin@gmail.com \\ ${ }^{2}$ Academic Adviser of Engineering Higher Education in Myanmar, Civil Engineering Department, Yangon \\ Technological University, Yangon, Myanmar, \\ Tel: +81-702-678-1507, e-mail: koike.eehe.project@gmail.com \\ ${ }^{3}$ Civil and Environmental Engineering Department, Engineering Faculty, Saitama University, Saitama City, \\ Japan, Tel: +81-048-858-3552, e-mail: dangji@mail.saitama-u.ac.jp
}

Received Date: February 3, 2018; Revised Date: July 14, 2021; Acceptance Date: December 8, 2021

\begin{abstract}
In general, the US codes such as the UBC-97 and ASCE-7 are widely used in developing countries including Myanmar, Syria, Philippines and so on. When the current seismic design guideline based on the UBC-97 and ACI 318-99 in Myanmar is assessed, several problems can be found in the following items: firstly, the fundamental period is not checked in modeling; secondly, reduction factor $R$ is introduced a priori for the base shear estimation. And finally, a limit state assessment is done only for Design Basic Earthquake (DBE) but not for other design earthquakes. As a result, adequate yield strength is not checked for Maximum Operational Earthquake (MOE). Then there is no way to assess the seismic safety of the ultimate limit state for Maximum Considered Earthquake (MCE). In order to solve these problems, a rationalized seismic design method for earthquake prone developing countries is proposed. A new seismic design method is developed for MOE and MCE with adequate yield acceleration and typical period of the building estimated by using pushover analysis. A simplified procedure to estimate the inelastic response for a given design spectrum is also proposed. Finally, this design procedure can provide a rational method to assess the seismic safety for the ultimate limit of the building.
\end{abstract}

Keyword: Buildings, Probability of failure, Quality control of construction, Reduction factor, Seismic design code, Yield acceleration.

\section{Introduction}

Earthquake-prone regions are world-widely located in the developed as well as developing countries which include Myanmar, Syria, Philippines and so on. Among some of countries, various seismic design guideline and/or codes have been established based on their local geophysical, industrialization and socio-economic needs and conditions. In general, the US codes such as the UBC-97 [14] and ASCE7-05 [2] are widely used in developing countries. Actually, those codes provided simple procedures based on essential principles such as Energy Conversion Rule or Equivalent Linearization based Capacity Spectrum Method to consider earthquake excitations for seismic design.

However, the direct transplantation from developed countries' codes might not always provide the adequate design code for those countries which have different earthquake environment or construction resource conditions. And it also should be noted that some developing countries are situated in earthquake-prone area, but the others are not. Therefore, 
the most appropriate design code should be adopted to assess the seismic safety for their geophysical and socio-economic conditions. And to be more important, those countries may have keen interest in how to mitigate it.

At first, in Myanmar, although many major faults have been found in this country, there is almost no seismic design guideline for buildings until recently. Presently, existing foreign building codes of the UBC-97 and ACI 318-99 [1] are introduced in some practical structural design and especially some design parameters such as seismic load and load combinations are a priori followed without tuning to fit the local seismic and economy characteristics. And some important steps and safety checks are mandated on the engineers' empirical calls.

Second, the Syrian seismic design code [16] follows the same approach as UBC-97 which provides straight forward procedures to calculate the seismic force. Relying on seismic site characteristics and structural properties certain seismic coefficients are chosen from tabulated data to be directly used to estimate the seismic force. This approach which depends mainly on a smooth elastic design spectrum does not require the use of Design Basis Earthquake (DBE) and Maximum Considered Earthquake (MCE). For the dynamic analysis, on the other hand, simplified quasi-static methods are often used to important RC buildings and infrastructures.

Advanced dynamic analysis methods applied to high-rise and irregular shaped buildings such as time history analysis are briefly mentioned in the Syrian design code. But these methods are not fully understood within the Syrian engineering community and therefore rarely used in real practice. Instead, reduction factor $(R)$ is used to calculate the seismic force for elastic design, although $R$ in principal reflects the inelastic behavior of the structure. The value of $R$ in the current code is only related to the structural lateral resisting system and building material and is taking as constant for a specific building structure.

Third, National Structural Code of the Philippines (NSCP) [17] has been revised several times since 1972. The seismic design procedure of this code also basically follows the same approach as UBC-97. Once the maximum acceleration response spectrum based on the geological and seismic condition is given, the base shear coefficient can be obtained as the ratio of this acceleration value divided by reduction factor, $R$. This base shear coefficient is used to the ultimate strength design of the building. In the seismic design procedure of NSCP, the displacement limit in terms of inter-story deflection angle is more severe than that of UBC-97.

From these investigation, three developing countries above mentioned follow the similar approach in the seismic design method as UBC-97 and they have some differences on the seismic design approach and an adequate use of reduction factor.

In order to discuss about the seismic design issue in the developing countries, as a typical example, the seismic design situation in Myanmar is investigated in detail.

When the current seismic design guideline in Myanmar is assessed, several problems can be found as the following items:

- Key Issue 1: The fundamental period is not checked in modeling.

- Key Issue 2: Reduction factor $R$ is introduced a priori for the base shear estimation.

- Key Issue 3: A limit state assessment is only necessary for DBE but not for other design earthquakes. 
Structural modeling is an important process for a designer. When the prototype model is decided, its fundamental period should be checked, at least in a simplified way, to confirm that it is inside a reasonable range comparing with the database of the current buildings, he might fail to select an appropriate structural system. Since the UBC-97does not mention any step to check the fundamental period given eplicitly, some local engineer might neglect some mistakes in the model.

Key issue 2 is related to the reduction factor, $R$, by which the UBC-97 develops an corresponding linear design procedure to evaluate the nonlinear response drift of the buildings and also to conduct safety assessment for structural elements. Since the reduction factor is decided by the structural seismic resistant system without consideration of structural period, so that, the capacity level of the structural model cannot be guaranteed, as it is difficult to obtain the practical solution without any change of reduction factor or the base shear. This study can provide a solution for this issue by introducing the yield acceleration to the current design method instead of reduction factor.

Generally, in the limit state design, the damage limit, repairable limit and ultimate failure limit should be checked due to the Maximum Operational Earthquake (MOE), the Design Basic Earthquake (DBE) and the Maximum Considered Earthquake (MCE). As mentioned in Key issue 3, the current design code requests to assess response check only for $\mathrm{DBE}$ but no for MCE. The building owner can request higher safety design by multiple different limit states in order to decrease the potential seismic risks. Is there any appropriateness in the single limit state assessment instead of the multiple targets? In this study, an updated seismic design method for earthquake prone developing countries is proposed. A case study is conducted for Myanmar.

\section{Problems in the Current Method}

\section{Fundamental Period}

The fundamental period, $T_{n}$, is calculated at the initial stage based on the formulae given in the UBC-97.

$$
T_{n}=0.0853 H^{3 / 4}
$$

Here $H$ is the building height (m).

But this period has not been referred in the current seismic design procedure in Myanmar. When a local engineer builds a numerical model, he/she should check the fundamental period of the model by Eigen-value analysis, mostly this checking process has been neglected.

In the practical stage, structural member sizes would be selected from the existing data base of building designs. It is not checked, however, whether this data base is appropriate or not. Once this procedure is fixed, a new higher quality member which is not included in the existing data base cannot be adopted as a structural member.

Misunderstanding of the formula of a fundamental period is also another issue causing some problems. The UBC-97code and Japanese code [8] prepare the design formula to control a structural modeling. Figure 1 shows a data base of high-rise buildings in Japan which shows practical samples of the possible building periods. 


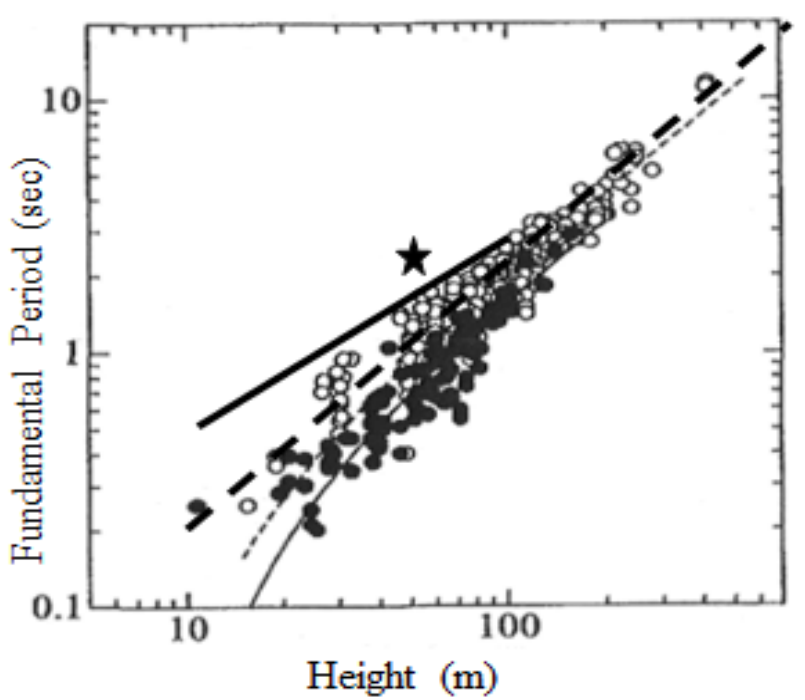

Figure 1. UBC-97 formula and Japanese code formula comparing with fundamental period and building height data base in Japan [13]

A thick line is given by the formula of UBC-97 and the thick broken line is for Japanese code. UBC-97 formula shows an approximate upper curve of the fundamental period of high-rise buildings in Japan. Using this UBC-97 curve, it can be used to check whether current model has a smaller period than this curve.

In Myanmar, a fundamental period (*) of the existing buildings shows a longer period than that of the UBC-97 curve as shown in Figure 1.

\section{Reduction Factor}

In the UBC-97, the reduction factor, $R$, is defined as the numerical coefficient representative of the inherent over-strength and global ductility capacity of lateral-force-resisting system [10]. Thus $R$ is a priori introduced in the initial stage of the design process as a representative coefficient of structural characteristics. Especially, the reduction factor for the yield acceleration, $A_{y}$, is defined [3] as following equation.

$$
R_{y}=\frac{S_{A}}{A_{y}}
$$

Here $A_{y}$ is an acceleration corresponding to the yield strength and $S_{A}$ is a response acceleration spectrum. In the current design code, design seismic load is based on only DBE, and $S_{A}$ is replaced as $S_{A}^{D B E}$.

In the UBC-97, the reduced base shear force, $V$, is defined as

$$
V=\frac{S_{A} W}{R}
$$

where $W$ is the weight of the structure. This definition is used to estimate the seismic load in design codes such as ASCE 7-05, IBC 2006 [6] and UBC-97. 


\section{Drift}

Applying the input seismic force of $V$ for a multi-story building as shown in Figure 2, the elastic response displacement, $\left\{u_{i}, i=1, \cdots n\right\}$, for each story can be obtained by solving an equilibrium equation for inertia loadings. When the relative story drifts, $\Delta u_{i}$, in which the $i_{-}{ }^{\text {th }}$ story drift can be given by $\Delta u_{i}=u_{i}-u_{i-1}$, is surveyed and obtained from the multi-story building response, the maximum relative story drift, $\Delta_{S 1}$, can be given by

$$
\Delta_{S 1}=\max \left|\Delta u_{i}\right|
$$

It should be noted that this maximum drift, $\Delta_{S 1}$, should be given for the reduced base shear force, $V$. Then the maximum relative story drift for unreduced base shear force is given by

$$
\Delta_{S 2}=R \Delta_{S 1}
$$

These two relative story drifts are shown in Figure 3.

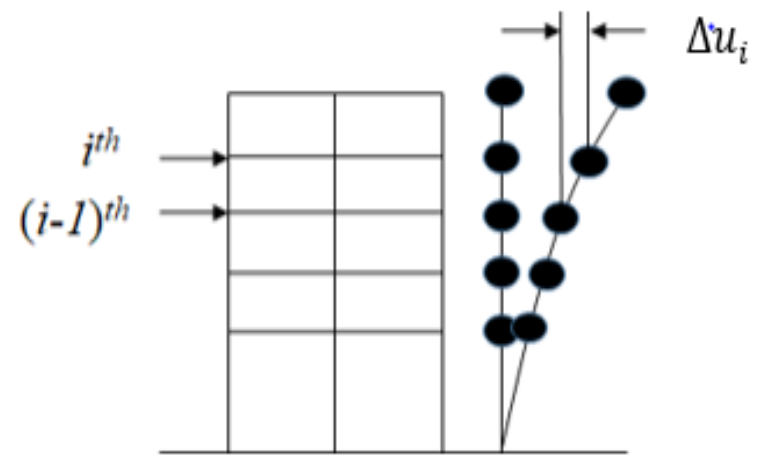

Figure 2. Relative displacement of the neighboring floors

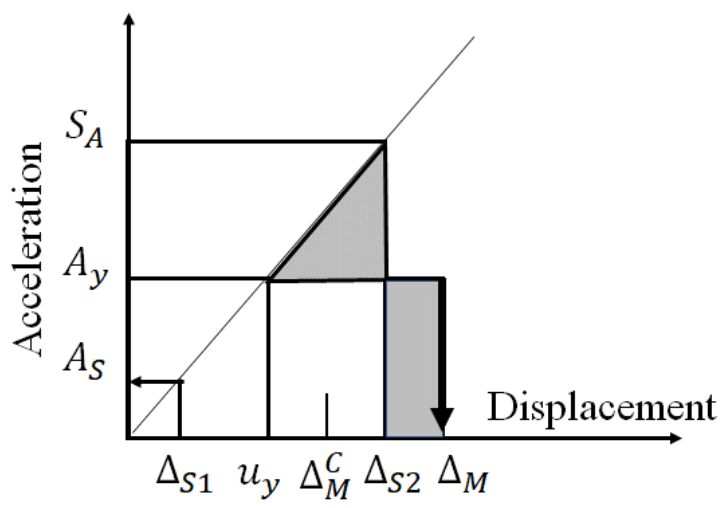

Figure 3. Illustration of accelerations and their corresponding displacements

In the practical seismic design in Myanmar, these two drifts, $\Delta_{S 1}$ and $\Delta_{S 2}$ have been used as mutually different drifts by some engineers, but many others use them without any distinction and they might adopt smaller drift of $\Delta_{S 1}$ instead of $\Delta_{S 2}$ for checking the building drift. This error will be avoided if the seismic load is defined as the base shear force without reduction. 


\section{Safety Assessment by Current Method}

The structural safety for MOE is assessed for the elastic yield strength, while the safety for MCE is checked for the inelastic limit displacement.

When a seismic acceleration corresponding to the seismic load exceeds the yield acceleration, the multi-story building produces the inelastic response [5]. There are several means to evaluate the inelastic response such as

(1) Estimation from Energy Conversion Rule based on a single-degree-of-freedomsystem model,

(2) Step by step time history integration based on the simplified bi-linear or other hysteresis model, and

(3) Equivalent Linearization based Capacity Spectrum Method (CSM).

Following the UBC-97, the first method is most often practiced one. And the maximum inelastic response is estimated by the following equation.

$$
\Delta_{M}^{C}=0.7 R \Delta_{S 1}
$$

Based on the Engineering Conversion Rule, on the other hand, the maximum inelastic displacement is formulated by

$$
\Delta_{M}=\mu \cdot u_{y}
$$

in which and $u_{y}$ is the yield displacement, and $\mu$ is called as ductility by which the maximum response is related with the yield displacement.

According to Equation (6) and Equation (7), both drifts can be shown in Figure 3, but $\Delta_{M}^{C}$ is smaller than $\Delta_{\mathrm{S} 2}$ and $\Delta_{\mathrm{M}}$ is larger than $\Delta_{\mathrm{S} 2}$. From the safety design aspect, the maximum drift must be larger than $\Delta_{\mathrm{S} 2}$. If so, $\Delta_{M}^{C}$ given by Eq.(6) cannot be accepted, although the equation (6) was obtained as an approximation on the applicability to a multi-degree-of-freedom system such as high-rise buildings [15].

When a critical limit value, $u_{c r}$, is given as a structural safety level, the safety assessment is checked by the following inequality formula.

$$
\Delta_{M}<u_{c r}
$$

If the inelastic response exceeds the critical limit value, the structural model should be updated until its response is small enough than the critical level. The possible solution to reduce the inelastic response $\Delta_{M}$ is to increase the present yield acceleration or to improve the ductility of structure in order to increase $u_{c \mathrm{r}}$.

Unfortunately, in the current code, there is not any description about the relationship between the reduction factor and the yield acceleration. By neglecting the original meaning of reduction factor, Myanmar's engineer can obtain appropriate yield acceleration $A_{y}^{*}$ by the proposed method in this study. Figure 4 shows the current seismic design procedure to be used in Myanmar. 


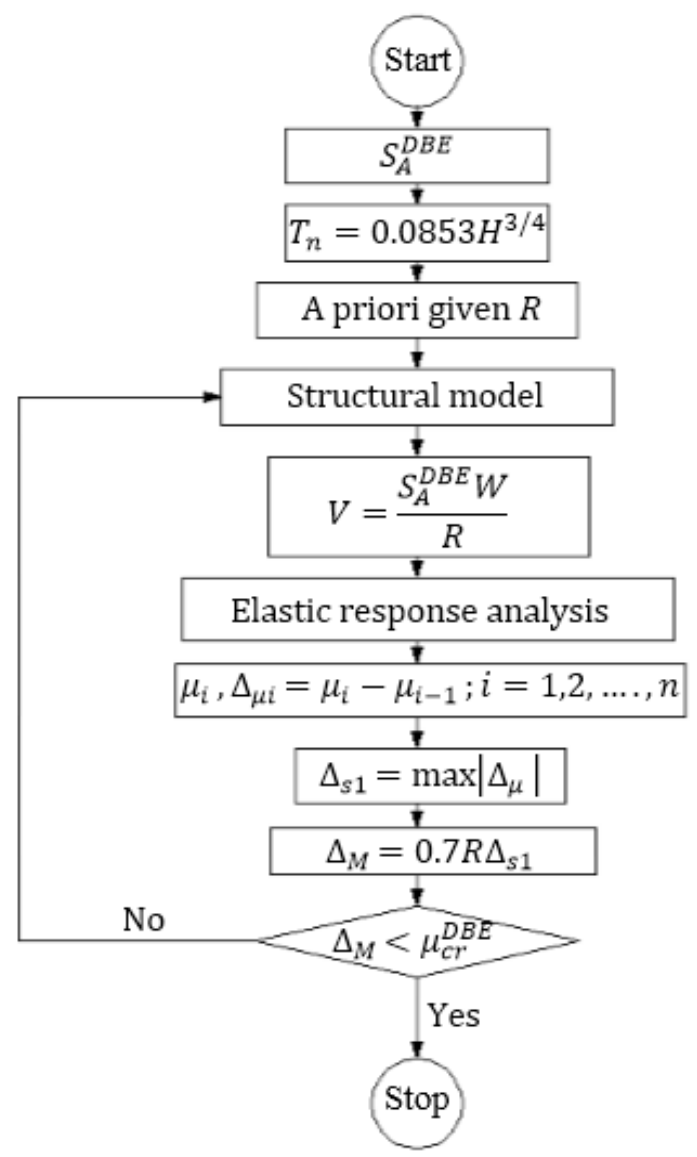

Figure 4. Flow chart of the current seismic design procedure

\section{A Limit State Assessment}

When a seismic safety assessment is conducted for multiple limit states, safety evaluation data will be accumulated, and the stakeholder will obtain much more accurate information for seismic risk assessment.

The stakeholder who has more accurate seismic risk information [9] can evaluate the effectiveness of his additional investment of seismic design and disaster mitigation action, and by decreasing insurance cost for future seismic risk. Therefore, the seismic risk analysis is an important tool to discuss on the multiple limit state assessment.

From this point of view, a single limit state approach for DBE is not enough for a building owner who is expecting higher safety under severe seismic risks. In general, several US code, ISO code, and any other codes of Japan and New Zealand recommend adopting multiple limit state assessment approach.

\section{A Rational Design Method Based on Yield Acceleration}

\section{Basic Procedure}

To avoid the misunderstood and double counting $R$, a new procedure is proposed without $R$. Instead of Energy Conversion Rule, the inelastic response is directly estimated by the dynamic response analysis of an elastoplastic hysteretic system which has a fundamental period, $T$, and the yield acceleration, $A_{y}$. 


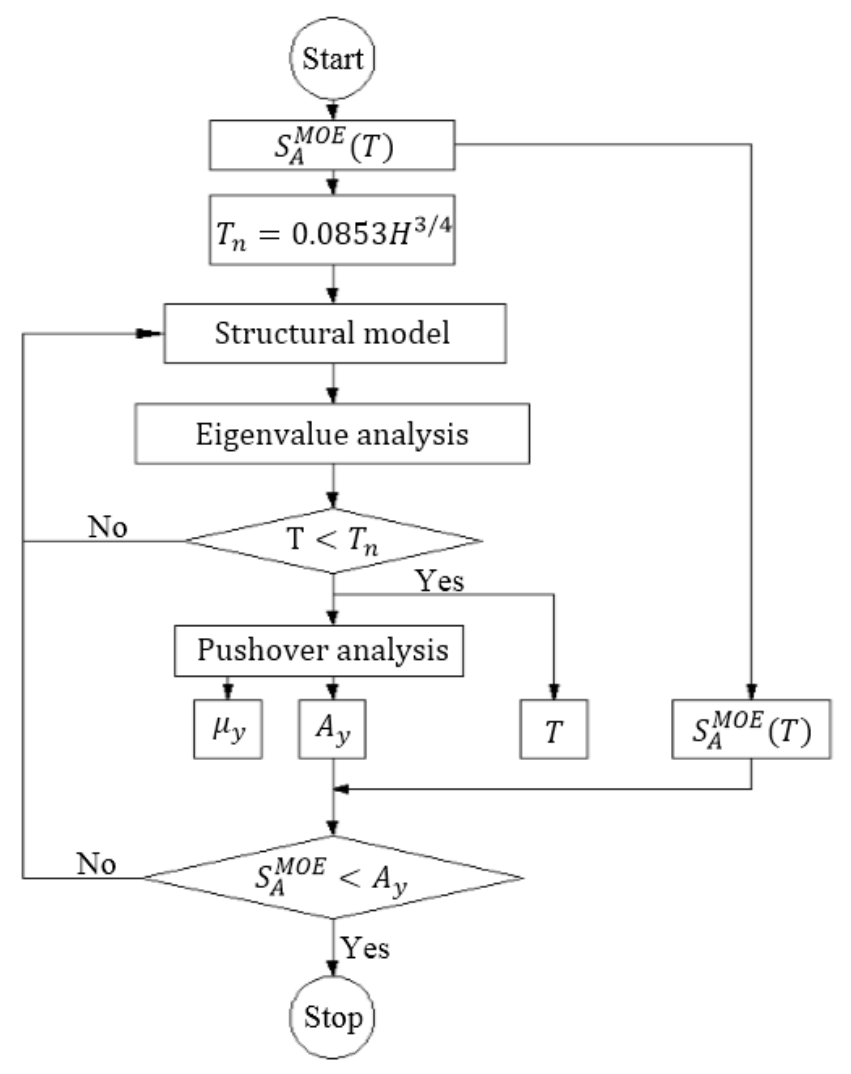

Figure 5. Flow chart of the proposed seismic design procedure for MOE

Figure 5 and 6 are seismic design flowchart for MOE and MCE. Then the response acceleration of $S_{A}^{M O E}$ is checked to be less than the yield acceleration. The inelastic response for MCE, on the other hand, is estimated by using the yield displacement and the ductility factor which is obtained from the maximum displacement data base of nonlinear dynamic responses of a single-degree-of-freedom system having various fundamental periods, $T$.

The ductility factor is calculated for any earthquake acceleration as a function of $T$ and $A_{y}$ as

$$
\mu^{M C E}=\mu\left(T, A_{y} \mid S_{A}^{M C E}\right)
$$

In this study, the ductility factor is obtained by using the simulated acceleration time history whose response spectrum is equal to the design spectrum given by the design code. The detail procedure will be described in the next chapter.

When the fundamental period and the yield acceleration are prepared, the input acceleration is assigned. And the corresponding ductility factor is given from Equation (9). Combining the ductility factor and the yield displacement at the critical point of the building, the inelastic response is given as

$$
\Delta_{M}=\mu^{M C E} \cdot u_{y}
$$

If the inelastic response exceeds the critical level for MCE, this design procedure is repeated by upgrading the yield acceleration or by modifying the fundamental period. 


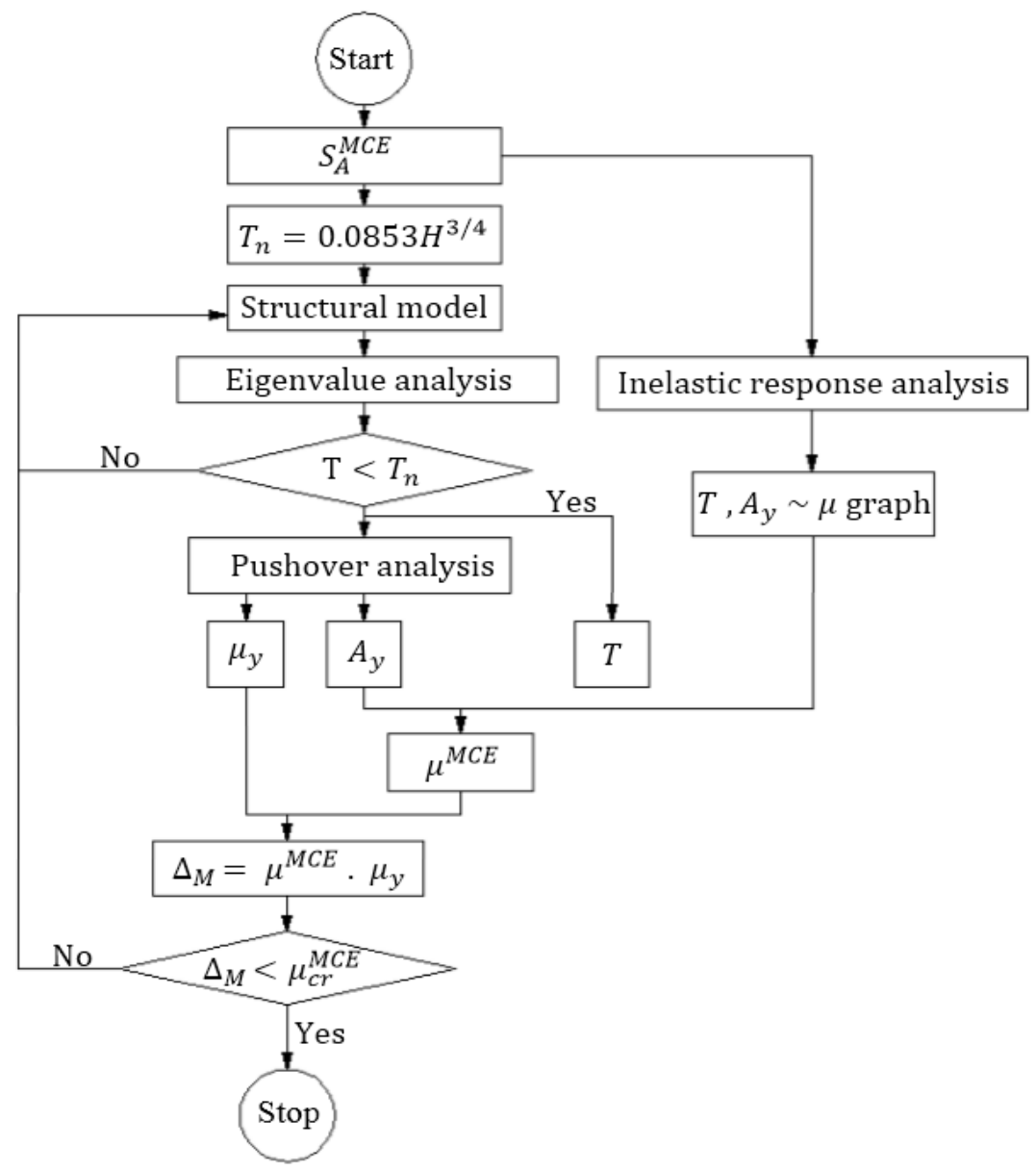

Figure 6. Flow chart of the proposed seismic design procedure for MCE

Two design methods are compared in Figures 8 and 9, in which the following items can be pointed out as disadvantage of the current method.

(1) An appropriate $A_{y}$ can be obtained from the assessment for MOE, but not for DBE.

(2) The reduction factor $R$ is a priori given in the current method, so the yield acceleration $A_{y}$ is also fixed by Equation (2). But under the fixed reduction factor, the current procedure cannot provide the final solution which is obtained by changing $A_{y}$.

(3) If the reduced seismic response $\Delta_{S 1}$ is used instead of $\Delta_{S 2}$, the maximum drift might be underestimated. Unfortunately, many engineers in the developing countries show the trend to adopt $\Delta_{S 1}$ instead of $\Delta_{S 2}$ in the drift assessment.

And the following items are summarized as advantage of the proposed method:

(1) Structural safety for MOE and MCE can be assessed based on the physically clear limit state points of failure mode.

(2) The reduction factor of $R$, which cannot control the yield acceleration, is not used in the seismic safety assessment procedure. Directly the yield acceleration is used to control as the structural safety parameter.

(3) At first, assumed yield acceleration is checked whether the maximum drift condition is satisfied or not. Once the yield level is checked, the elastic structural analysis is executed to assess the safety of the structural elements.

(4) Human error such as misunderstanding of $\Delta_{S 1}$ instead of $\Delta_{S 2}$ can be avoided. 
(5) Formula of $\Delta_{M}$ in the proposed method is derived from the theoretical basis. Any time history data of the past earthquakes and the modified wave forms to be compatible with design response spectra can be utilized to estimate the maximum drift.

\section{Safety Assessment by the Proposed method}

A sample of structural model is introduced to discuss the proposed design method. Model data is summarized in Table 1. Figure 7 shows a seismic loading model in this study. Figure 8 shows the relationship between the ductility factor and fundamental period of the structural model. The curve of Critical level in these figures means the value of the critical displacement divided by the yield displacement.

Table 1. Critical Displacement at the Check Point for DBE and MCE

\begin{tabular}{|c|c|c|c|c|}
\hline Item & Symbol & Unit & DBE & MCE \\
\hline Floor height & $\mathrm{h}$ & $\mathrm{m}$ & 3 & 3 \\
\hline Critical displacement & $\mu_{c r}$ & $\mathrm{~m}$ & 0.06 & 0.12 \\
\hline Yield acceleration & $A_{y}$ & $\mathrm{~g}$ & 0.5 & 0.5 \\
\hline
\end{tabular}

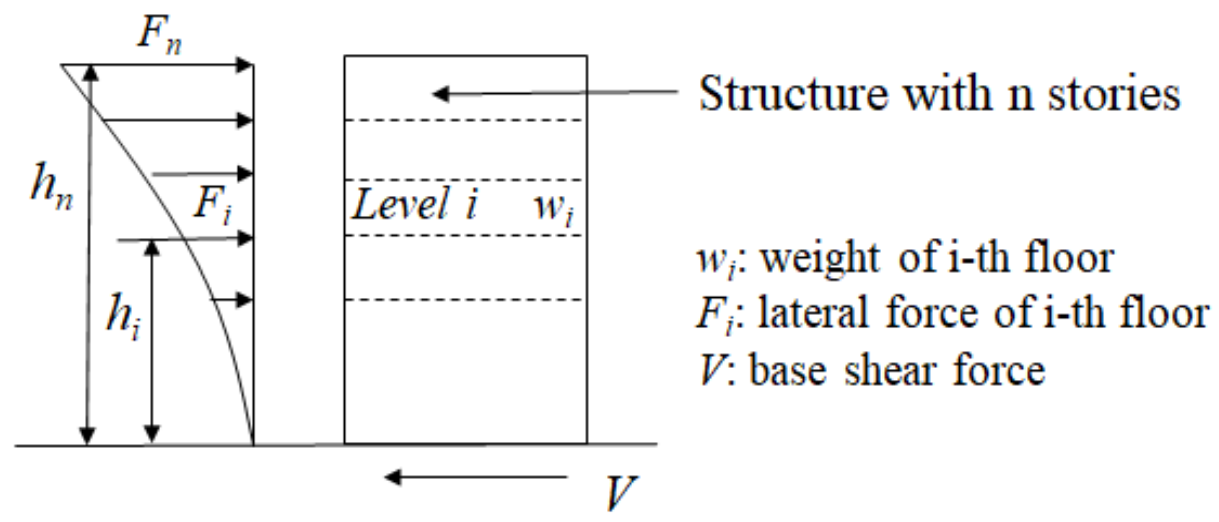

Figure 7. Distribution of seismic forces [2]

The curve of seismic load means the seismic response in terms of ductility factor. In Figure 8 and 9, the modified Kobe earthquake data is introduced as an input seismic load of MCE level. The detail calculation procedure of the inelastic response is given in the next chapter.

In Figure 8, the seismic load curve is less than the critical level over the whole period. Therefore, the structure having $A_{y}=0.5 \mathrm{~g}$ is still seismically safe for MCE class loading. But if a lower yield acceleration is introduced such as $A_{y}=0.25 \mathrm{~g}$ as shown in Figure 9, the structural response exceeds the critical level at $0.3 \mathrm{sec}$ to $0.8 \mathrm{sec}$. From the view point of seismic design, the yielding acceleration should be upgraded in order to keep the seismic inelastic performance. 


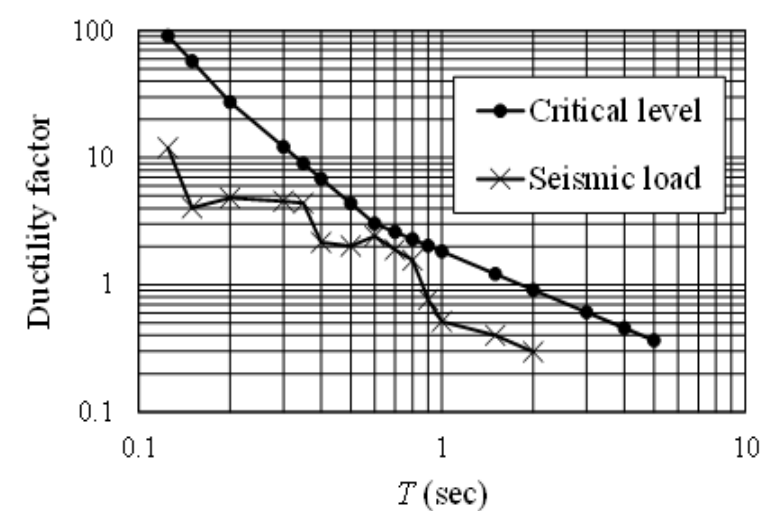

Figure 8. A seismic load of MCE not critical level

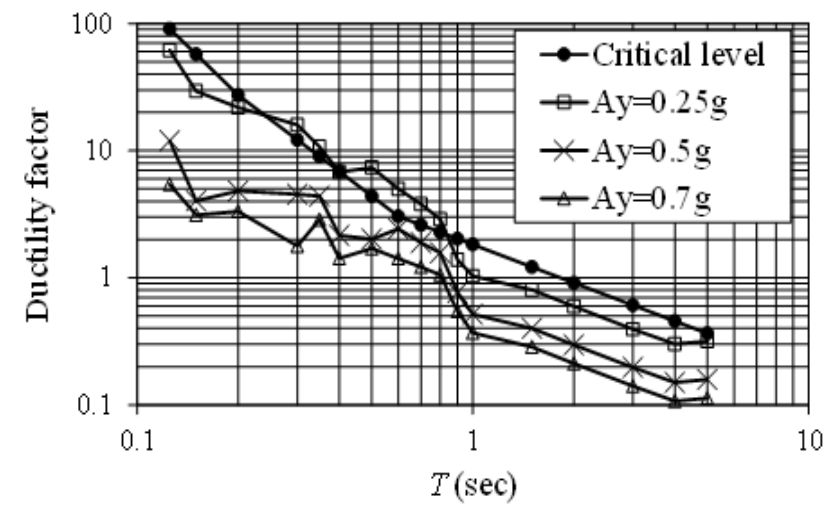

Figure 9. Upgrading Ay improves exceeding the the seismic safety

\section{Ductility Factor Obtained from Yield Acceleration Spectrum}

\section{Yield Acceleration Spectrum}

The yield acceleration of a single-degree-of-freedom system can be calculated by Newmark's method [11]. Once a ductility factor is assigned, the corresponding yield acceleration can be given for typical periods.

Strong motion data of earthquake acceleration are collected from ground motions measured at USA, Japan and Taiwan such as El Centro 1940, Kobe 1995 and Chi Chi 1999.These three different earthquakes show their own characteristic yield acceleration curves for the ductility factor of 5 as shown in Figure 10. Among them, Kobe and El Centro curves show a similar profile, but Chi Chi curve is different from the others.

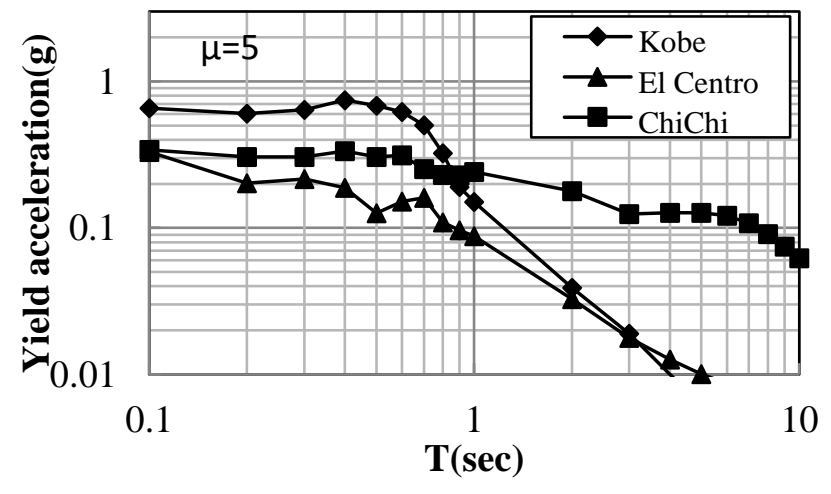

Figure 10. Yield acceleration of unmodified ground motion for three different earthquakes

\section{Yield Acceleration Spectrum Compatible with A Design Spectrum}

The current seismic design guidelines provide a design response spectrum for each performance level. To meet this requirement, artificially generated strong motion data which is compatible with the current design spectrum [12] is simulated by the method proposed by JHRA [7]. The phase difference of the simulated ground motion is given with a white noise model which might be different from that of measured ground motions. 
The simulated ground motion is generated to be compatible with the design response acceleration spectrum specified by ISO. The phase characteristic is randomly given with a white noise. As the real ground motion, on the other hand, Kobe earthquake data is adopted, but its acceleration is modified to meet the requirement that the response acceleration spectrum should be the same as that of ISO [4].

As a result, the response acceleration spectrum of two earthquakes should be the same as that of the ISO. But the phase characteristics for these two earthquakes are not identical.

From the numerical results obtained in Figures 11, it is concluded that the yield acceleration spectrum can be evaluated for each ductility factor. The curves for the ductility factor of larger than 5 are converged into the same value in all the figures.

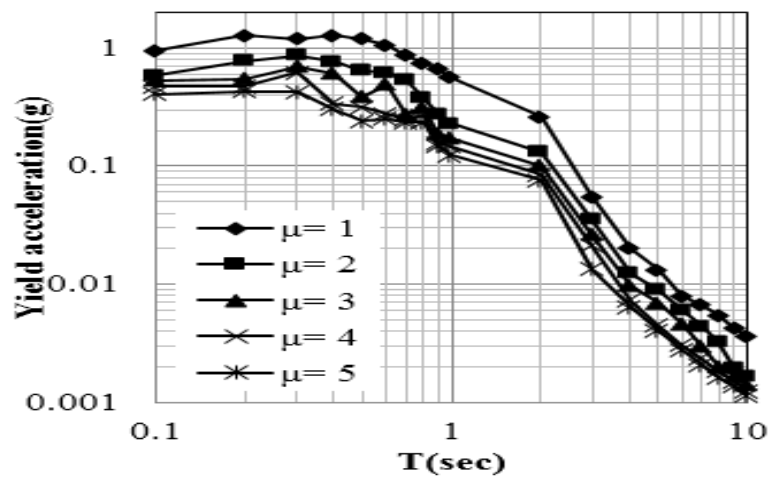

(a)Random, ISO

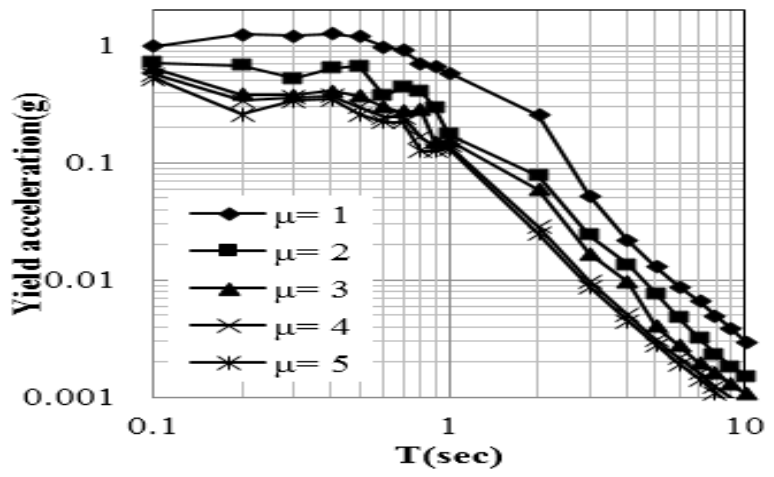

(b) Kobe, ISO

Figure 11. Effect of the phase difference

\section{Conclusions}

The UBC-97 has been world-widely adopted as a seismic design code for buildings in the developing countries. But, in these countries, this code has been misunderstood in the process to check the appropriateness of the structural modeling, to estimate the inelastic response and to assess the safety at the limit state. As a result, the safety assessment for buildings has been under-estimated. To solve this problem, a new design method is proposed. The following points can be summarized as the problem and its solution:

(1) In the current design method, the reduction factor, $R$, is a priori given as the code requirement. But when the structural response exceeds the critical level, the optimal solution cannot be obtained without decreasing reduction factor. In order to solve this unreasonable requirement, many nonlinear analyses have been repeated. But this problem can be solved by reforming the seismic design frame work with the yield acceleration, $A_{y}$, instead of the reduction factor.

(2) In the proposed design method, the maximum inelastic drift, $\Delta_{M}$, is obtained from the ductility factor, $\mu$, and the yield displacement, $u_{y}$. In this method, the ductility factor is directly estimated by the fundamental period of $T$ and the yield acceleration, $A_{y}$, from the maximum displacement data base which is produced from the dynamic response analysis for a single-degree-of-freedom system. 
(3) Currently, earthquake of DBE has been adopted for seismic assessment. But the repairable limit for DBE is related not only on the physical characteristics but also on the maintenance strategy, so DBE is not appropriate for seismic safety assessment. In the proposed design method, the yield strength in terms of yield acceleration should be checked to be large enough for the structural response by earthquake load of MOE. Using this yielding condition, the maximum inelastic drift is also checked for the response displacement by earthquake load of MCE.

\section{References}

[1] American Concrete Institute (ACI), Building Code Requirements for Structural Concrete (ACI 318-99), Farmington Hills, Michigan, Uunited States, 1999.

[2] American Society of Civil Engineering (ASCE), Minimum Design Loads for Buildings and Other Structures, ASCE/SEI7-05, Reston, Virginia, United States, 2005.

[3] A.K. Chopra, Earthquake Dynamics of Structures A Primer, $2^{\text {nd }}$ Edition, Earthquake Engineering Research Institute, Oakland, California, United States, 2005.

[4] Committee European de Normalization (ISO), Design of Structures for Earthquake Resistance, Part 1: General Rules, Seismic Actions and Rules for Buildings European Standard (EN 1998-1: 2004, Eurocode-8), CEN, Brussels, Belgium, 2004.

[5] S.W. Han, and A.K. Chopra, "Approximate incremental dynamic analysis using the modal pushover analysis procedure," Earthquake Engineering and Structural Dynamics, Vol. 35, No. 15, pp. 1853-1873, 2006.

[6] International Code Council (ICC), International Building Code (IBC-06), Washington D.C., United States, 2006.

[7] Japan Highway Road Association (JHRA), Guideline of Highway Road Bridge Design in Japan, Tokyo, Japan, 2004.

[8] JSCE Earthquake Engineering Committee, "Present state of level 2 earthquake motion," Journal of JSCE, No.675/I-55, pp. 15-25, 2001.

[9] T. Koike, "Chapter 23: Seismic risk analysis and management of civil infrastructure systems," In Handbook of Seismic Risk Analysis and Management of Civil Infrastructure Systems, S. Tesfamariam, and K. Goda, eds.: Woodhead Publishing Limited, Sawston, Cambridge, United Kingdom, 2013.

[10] E. Miranda, and V.V. Bertero, "Evaluation of strength reduction factors for earthquakeresistant design," Earthquake Spectra, Vol. 10, No. 2, pp. 357-379, 1994.

[11] N.M. Newmark, "A method of computation for structural dynamics," Journal of the Engineering Mechanics Division, Vol. 85, No. 3, pp. 67-94, 1959.

[12] N. Newmark, and W.J. Hall, Earthquake Spectra and Design, EERI Monographs, Oakland, California, United States, 1982.

[13] S. Ohta, and M. Ishida, "Seismic performance assessment by using building fundamental periods," In: The 5th Disaster Prevention Symposium for Structures: No. 8 in the Session of Seismic Investigation for Existing Building, Symposium conducted at Architectural Institute of Japan (AIJ), Tokyo, Japan, 2004.

[14] International Code Council (ICC), Uniform Building Code (UBC-97), Washington D.C., United States, 1997. 
[15] G.R. Searer, and S.A. Freeman, "Design draft requirements for long-period structures," In: The 13th World Conference on Earthquake Engineering, Vancouver, British Columbia, Canada, Paper No. 3292, 2004.

[16] Syrian Engineering Association, Syrian Engineering Building Code, SEA Publication, Damascas, Syria, 2004.

[17] Association of Structural Engineering of the Philippines Inc. (ASEP), National Structural Code of the Philippines, Vol. 1, $6^{\text {th }}$ Edition, $4^{\text {th }}$ Printing-Buildings, Towers and Other Vertical Structures, ASEP, Philippines, 2010. 